\title{
Features of the functioning of a geographically distributed medical organization in Russia
}

\author{
$A$ Dubgorn $^{1, *}, S$ Svetunkov ${ }^{1}$, and $A$ Borremans ${ }^{1}$ \\ ${ }^{1}$ Peter the Great St. 29, 195251, St. Petersburg, Russia
}

\begin{abstract}
The paper describes the process of modeling functional structure of a geographically distributed commercial medical organization, based on a case of specific medical organization in Russian Federation. Based on the reference model of a commercial medical organization functional structure the main, management and supporting functions were analyzed. Based on the analysis and using the Archi enterprise architecture tool the functional structure taking into account the issue of geographical distribution was developed. The result of the research can be used as a starting point for developing a system of business processes as well as information requirements of the geographically distributed commercial medical organization.
\end{abstract}

\section{Introduction}

The services of commercial medical organizations are in high demand when talking about Russian Federation. The difficult structure of government paid medical services as well as the need for a long wait for them lead to popularity of commercial medicine. Thus, the niche of multidisciplinary medical centers is high competitive in Russian Federation. The research of commercial medicine market of RF [5] indicated special demand for paid medical services in large cities (Moscow, St. Petersburg, Kazan), which tells about high competition level there. The regional demand is more focused on free (paid by the government) medicine, but large commercial medical organizations are trying to change the situation by opening their branches or offering the franchise business model to local entrepreneurships. For both of the options there is a strong need in a pre-developed system of business processes described in order to shorten the preparatory period of new medical center opening.

In order to model the system of business processes and prepare the regulatory documents for a new medical center, opened as a branch of existing medical organization, there is a need to develop a functional structure first, which will be adoptable to use it when the organization decides to expand its activities geographically.

\section{Materials and Methods}

The paper is based on materials of research work realized by its authors for one of the

* Corresponding author: dubgorn@spbstu.ru 
geographically distributed commercial medical organization, the headquarter of which is located in St. Petersburg. The strategy of indicated organization's development indicated the opening of new branches in different regions of RF according to market research results. During the last 5 years this organization developed 4 medical organizations in various RF regions. Some of them were opened "from scratch", some were organized on a basis of existing government medical organizations (bought from the state). The main issue for the top management of named medical organization was to spread same quality standards (developed on a process approach basis) and centralize the governing activities for all branches.

According to the above described request of commercial medical organization and taking into account the benchmarking results a functional structure was developed in order to be analyzed as an initial point to model and implement business processes in different branches and to centralize some functions' governing activities.

Enterprise architecture [2, 3, 9, 10], including ArchiMate modeling language [14] and process management [1] are main methods used in the present research.

\section{Results}

The functional model of the organization in this work is understood as a graphical representation of the system of business functions of the organization. A business function refers to the category of operations performed on an ongoing basis that is necessary to support the organization's business purpose. The definition of a set of such operations allows at the conceptual level to identify the business functions of the organization $[6,8]$. The first step needed to proceed with identifying business functions is their high-level categorization.

The categorization of functions as primary and support activities in the concept of forming a value chain was first proposed by M. Porter in 1985 [12]. A chain is a collection of activities (which are inherently business functions) that are performed in a company in order to create value for the end user. Value creation equates to the creation of added value, which in turn leads to a competitive advantage. Ultimately, the added value also creates higher profitability for the organization.

The value chain concept links systems and activities to each other and demonstrates how their implementation affects costs and benefits. Hence, value chain analysis helps clarify where the sources of value and loss in an organization can be found. The classical value chain described by M. Porter is presented in the figure 1. 


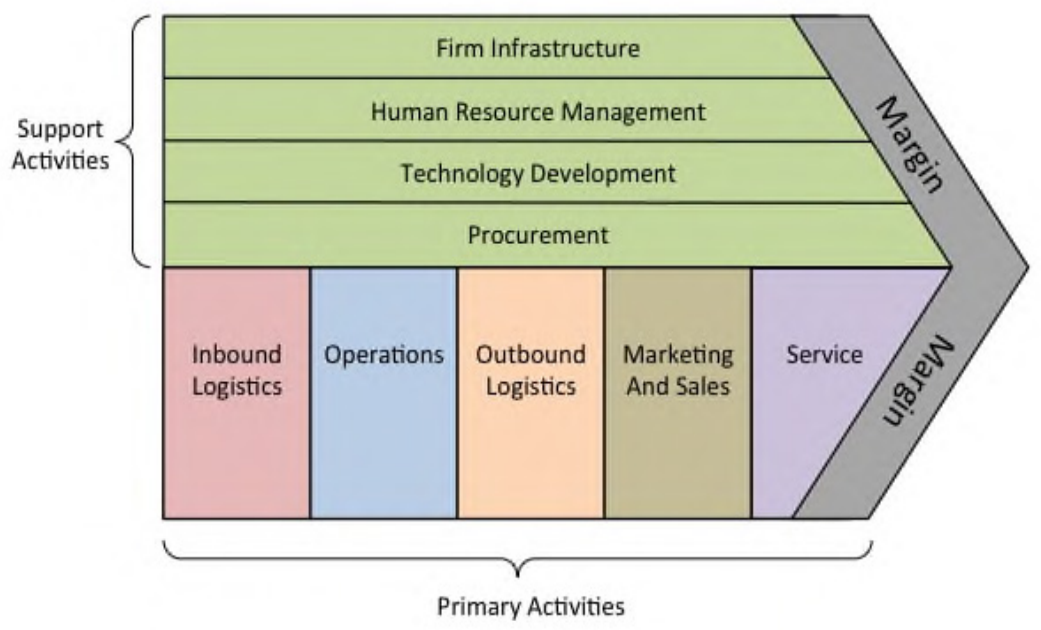

Fig. 1. M. Porter's Value Chain [12].

Thus, the use of the concept of the value chain allows highlighting the main and supporting business functions when developing the functional model of the organization. In addition to these functions, the author's functional model implies the allocation of management functions. Most of the approaches, including M. Porter's, imply that management functions are part of supporting functions, since they do not apply to those where there is direct contact with the client and not directly influence on the added value. However, methodologies that imply further detailing of enlarged functional blocks, for example, approaches to the selection of functions for the purpose of further decomposition of business processes that ensure their implementation [1,6], allocate control functions into a separate category. At the same time, the set of management functions in this context cannot be called universal, their set will differ depending on the characteristics of a particular organization.

The suitable point to start developing a functional structure of an organization is to look for industry best practices and reference models. In the case of present research, a reference model of a medical organization's functional structure [4] was used as a basis to analyze main (core), management and supporting activities. Each function presented in the reference model was analyzed in accordance to geographically spread branches' requirements. The results of the analysis are presented in table 1 .

Table 1. Analysis of the medical organization business functions in context of its geographically distribution.

\begin{tabular}{|c|c|c|}
\hline Level of BF & Business function (BF) & $\begin{array}{c}\text { How to be realized in } \\
\text { branch }\end{array}$ \\
\hline Core & Outpatient reception & Only in-place \\
\hline Core & In-patient reception & Only in-place \\
\hline Core & Occupational medicine & Only in-place \\
\hline Core & Emergency medicine & Only in-place \\
\hline Core & Rehabilitation treatment & Only in-place \\
\hline Core & Dentistry & Only in-place \\
\hline Core & $\begin{array}{c}\text { Laboratory and instrumental } \\
\text { services }\end{array}$ & Only in-place \\
\hline
\end{tabular}




\begin{tabular}{|c|c|c|}
\hline Core & Telemedicine & $\begin{array}{c}\text { Can be outsourced, from one } \\
\text { place for all centers }\end{array}$ \\
\hline Core & Dispensing drugs & Only in-place \\
\hline Core & Drugs production & $\begin{array}{c}\text { Can be outsourced for some } \\
\text { drugs }\end{array}$ \\
\hline Core & Drugs retail & Only in-place \\
\hline Core & $\begin{array}{c}\text { Educational services and their } \\
\text { support }\end{array}$ & $\begin{array}{c}\text { Can be outsourced, realized } \\
\text { as an online service }\end{array}$ \\
\hline Core & $\begin{array}{c}\text { Scientific and experimental } \\
\text { research }\end{array}$ & Only in-place \\
\hline Management & Human Resources Management & $\begin{array}{c}\text { Can be outsourced with only } \\
\text { administrative tasks in-place }\end{array}$ \\
\hline Management & Financial Management & $\begin{array}{c}\text { Can be outsourced with only } \\
\text { administrative tasks in-place }\end{array}$ \\
\hline Management & Marketing Management & $\begin{array}{c}\text { Can be outsourced with only } \\
\text { administrative tasks in-place }\end{array}$ \\
\hline Management & IT Management & $\begin{array}{c}\text { Can be outsourced with only } \\
\text { administrative tasks in-place }\end{array}$ \\
\hline Management & Development & Only in the headquarter \\
\hline Management & Quality Management & Only in the headquarter \\
\hline Supporting & Logistics \& Supply & $\begin{array}{l}\text { Can be outsourced with only } \\
\text { administrative tasks in-place }\end{array}$ \\
\hline Supporting & Assets Management & Mostly in-place \\
\hline Supporting & Legal Support & $\begin{array}{c}\text { Can be outsourced with only } \\
\text { administrative tasks in-place }\end{array}$ \\
\hline
\end{tabular}

It has to be noticed, that the need of particular function to be realized in-place or outsourced was analyzed in accordance to specific internal and external environment of one particular geographically distributed medical organization. One of the main tools to provide the analysis was expert review.

Based on the results of the analysis a model of geographically distributed medical organization's functional structure was developed. The ArchiMate enterprise architecture modeling language and Archi software tool were used to create the model. The results are represented in the figure 2 . 


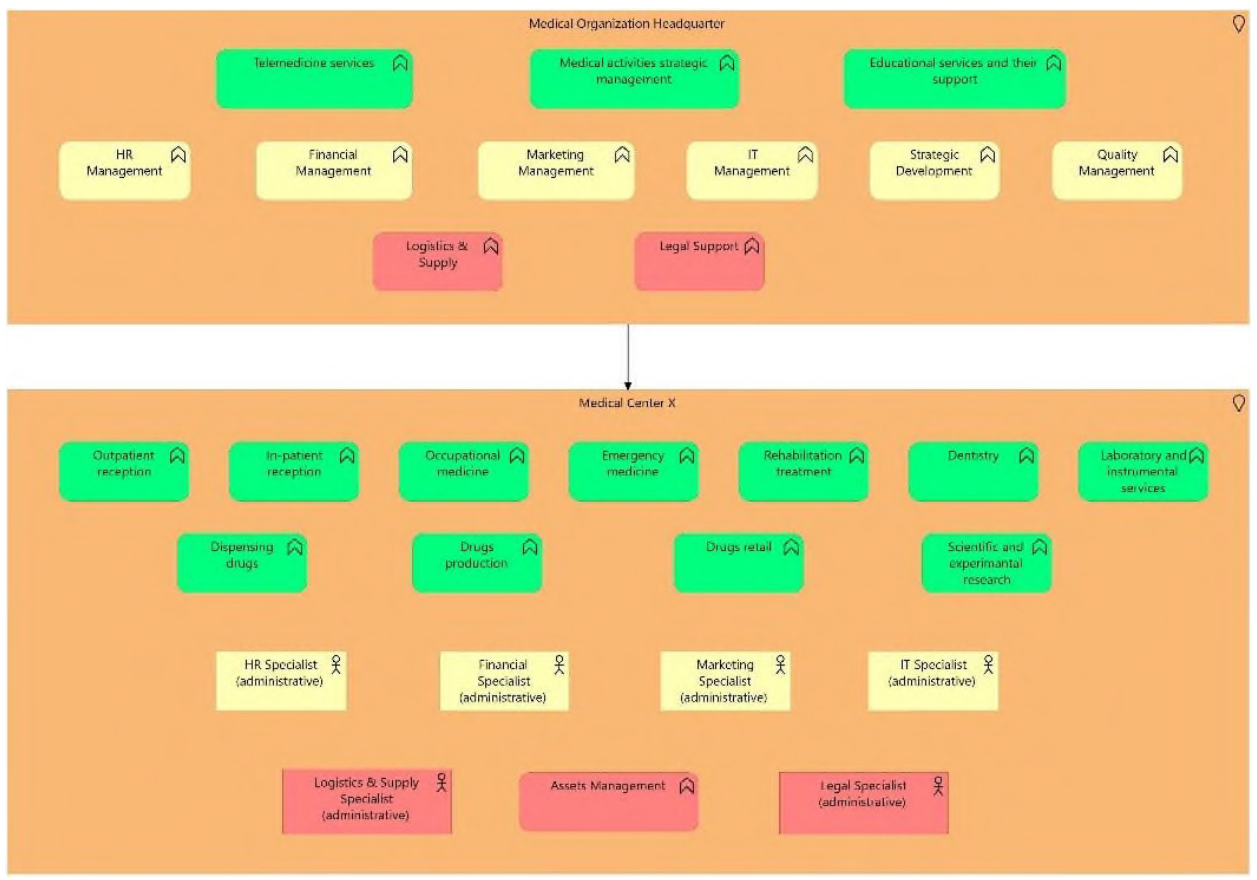

Fig. 2. Geographically distributed medical organization's functional structure.

The green "Function" elements of Figure2 show main (medical) functions, the yellow "Function" and "Business Role" elements show management functions and the red "Function" and "Business Role" elements show supporting functions of the headquarter and branches of geographically distributed medical organization. We see that most of the main functions, which in this case refer to medical services, are realized in medical centers, while management and supporting functions can be mostly centralized in the headquarter leaving only administrative specialists in-place.

\section{Discussion}

The presented model of geographically distributed medical organization's functional structure can be used as a starting point to develop a system of business processes for new medical centers opening as its branches. At the same time the model can be used to identify information requirements of both headquarter and medical centers in order to develop the IT architecture of the whole medical organization [7, 10, 11]. As the enterprise architecture approach involves the detailing of developed models on a level needed to solve particular tasks, it can also be used as a basis of creating organizational structure of a company.

In the case of this research the developed functional structure supported the decision to create a Management Company within the business architecture of the geographically distributed medical organization in order to regulate the relationships of the headquarters and the branches.

\section{Conclusion}

Based on a case of a large Russian commercial medical organization, which tends to open more medical centers in different regions of RF, a model of functional structure was created. This model can help to start business process management activities in new 
branches and also reorganize the complex structure of management within the organization. The geographical distribution of the organization was considered as a main factor of developing the structure of main, management and supporting functions. The future research will be devoted to analyzing the information requirements of particular business functions in order to develop an IT Service architecture for the geographically distributed medical organization.

\section{Acknowledgements}

The reported study was funded by RFBR according to the research project №20-01000955.

\section{References}

1. J. Becker, M. Kugeler, M. Rosemann, Process Management. A guide for the Design of Business Processes (Springer-Verlag, 2011)

2. Capgemini Enterprise Architecture Management, https://www.capgemini.com/dede/resources/enterprise-architecture-management-en/

3. L.G. Cretu, Enterprise Architecture Frameworks: Integrating Business Processes with IT Infrastructure (Apple Academic Press, Oakville, 2014)

4. A. Dubgorn, I. Ilin, A. Levina, A. Borremans, Proceedings of the 33rd International Business Information Management Association Conference, IBIMA 2019: Education Excellence and Innovation Management through Vision 2020, 5129-5137 (2019)

5. Ernst\&Young commercial medicine research report

6. I. Ilin, A. Levina, A. Lepekhin, S. Kalyazina, Business Requirements to the IT Architecture: A Case of a Healthcare Organization (2019)

7. O. Iljashenko, I. Bagaeva, A. Levina, Strategy for establishment of personnel KPI at health care organization digital transformation. IOP Conference Series: Materials Science and Engineering (2019)

8. S. Krasnov, S. Sergeev, E. Zotova, N. Grashchenko, Algorithm of optimal management for the efficient use of energy resources. E3S Web of Conferences (2019)

9. M. Lankhorst, Enterprise Architecture at Work. Modelling, Communication, Analysis (Springer-Verlag, 2013)

10. M. Op’t Land, E. Proper, M. Waage, J. Cloo, C. Steghuis, Enterprise Architecture. Creating Value by Informed Governance (Springer Verlag, Berlin, 2009)

11. M.A. Pfannstiel, C. Rasche, Service Design and Service Thinking in Healthcare and Hospital Management (Springer, Cham, 2019)

12. M. Porter, Competitive Advantage: Creating and Sustaining Superior Performance. Harvard Business Review (1998)

13. The Practical Guide for SOA in Health Care. A real-world approach to planning, designing, and deploying SOA. Ver. 1.0. Healthcare Services Specification Project, Health Level Seven, Object Management Group (2008)

14. Welcome to the ArchiMate ${ }^{\circledR} 3.1$ Specification, a Standard of The Open Group, https://pubs.opengroup.org/architecture/archimate3-doc/ 